\title{
SIMPLIT: Ensuring technology usability for the elderly
}

\author{
J.V. Durá ${ }^{1 *}$, José Laparra-Hernández ${ }^{1}$, Rakel Poveda ${ }^{1}$, Raquel Marzo ${ }^{1}$, Amparo \\ López ${ }^{1}$, Clara Bollaín ${ }^{1}$ \\ ${ }^{1}$ Instituto de Biomecánica de Valencia, Universitat Politècnica de València, Spain \\ *Corresponding author (juan.dura@ibv.upv.es)
}

\begin{abstract}
Purpose The aim of this work is to establish a reliable methodology to test if a product is simple, practical, and userfriendly for the elderly. We pursue a twofold objective: (i) to respond to companies that want to be responsive to this increasingly demanding group; (ii) to guarantee that the certified products are easy to use for the elderly. The methodology will consist of reliable protocols according to the quality required by the recognised certification bodies-in the Spanish case AENOR. Method The method we followed involves several steps: (i) assure the participation of elderly people with the collaboration one of the most important Spanish elderly associations: UDP 1.500 .000 members; (ii) a field study (441 questionnaires) to obtain and classify the problems that elderly people experience with products; (iii) define testing protocols based on the fulfilling mandatory standards and usability tests. Usability tests are based on a hierarchical classification of tasks and a categorical classification of the problems. We obtained data on the effectiveness, efficiency and ease of learning, with which elderly people achieve specified goals in particular environments; (iv) checking the process with 4 practical cases that cover low-tech and hi-tech products: the wardrobe, an activity park, an oven, and a tablet computer; (v) submitting protocols satisfying the requirements of a quality certification body. Results \& Discussion As result we have developed a methodology with four steps. (i) Verification of the regulation (standards). We check compliance with the legislation on safety and ergonomics of the product to guarantee that it fulfills the minimum conditions. (ii) Ease-ofuse tests. We analyse the learning of tasks, ease-of-use and efficacy of implementation, performing a diagnosis of the product based also on the assessment of elderly users. (iii) Global product diagnosis. (iv) Quality verification. We make sure that the product diagnosis is performed systematically by audit of the certification body (AENOR). The assessment of effectiveness, efficiency and ease of learning, are tasks classified on 4 levels: (a) basic \& high frequency, (b) basic \& low frequency, (c) no basic \& high frequency, (d) no basic \& low frequency. The problems that appear during the tasks are classified in 18 categories (e.g. dexterity, reaching, equilibrium, etc.). This problem classification facilitates the search for solutions and helps designers to improve the design. This methodology has resulted in a new certificate: SIMPLIT. SIMPLIT is a quality label that guarantees that products have been developed with a design aimed at elderly people. This certificate is now being used and several products have obtained the quality label. Moreover, we use the methodology in projects to develop new products for the elderly.
\end{abstract}

Keywords: usability, certification, effectiveness, efficiency, ease of learning

\section{INTRODUCTION}

Older population has become a powerful consumer group, accounting for $26 \%$ of all retail sales. This population group is growing, and its impact on the Spanish society is becoming more and more important. Currently, it represents approximately $6.7 \%$ of the total population, but it is estimated to rise over $30 \%$ by 2050 . However, more than $80 \%$ of the older persons believe that Spanish companies never, or hardly ever, have them in mind when it comes to designing their products ${ }^{1}$.

Older persons detect serious problems regarding the usability of many products. This often leads to falling into complete disuse or not taking advantage of their full functional potential. Design focusing on older people allows achieving age-friendly products. The aim of this work is to develop a certificate that certifies that a product is comfortable, intuitive and easy to use.

\begin{abstract}
Methodology
The methodology is divided in two main blocks. The methods used in order to identify problems and products categories. And the methods used in order to define the protocols.
\end{abstract}

\section{Identification of problems and product catego- ries}

Firstly, a field survey with standardized open-ended interviews $^{2}$ (the same open-ended questions are asked to all interviewees) with 500 old persons (Table 1) and 350 stores. The goal of the interviews is to obtain information in order to define a map that relates products categories and problems. The definition of the interviews is based in focus groups with older people and the collaboration of one of the most important Spanish older persons associations: UDP 1.500.000 members (www.mayoresudp.org). 
The older persons that participate in the field survey live independently in their homes. The field survey covers different sizes of cities (Table 1).

Table 1. Distribution of older persons

\begin{tabular}{|c|c|c|c|c|}
\hline City size & Age & Women & Men & TOTAL \\
\hline \multirow{3}{*}{$\begin{array}{l}0 \\
2.000\end{array}$} & $50-65$ & 14 & 14 & 28 \\
\hline & $65-80$ & 12 & 9 & 21 \\
\hline & $>80$ & 4 & 2 & 6 \\
\hline \multirow{3}{*}{$\begin{array}{l}2.001 \\
10.000\end{array}$} & $50-65$ & 23 & 22 & 45 \\
\hline & $65-80$ & 19 & 15 & 34 \\
\hline & $>80$ & 6 & 3 & 9 \\
\hline \multirow{3}{*}{$\begin{array}{l}10.001 \\
50.000\end{array}$} & $50-65$ & 27 & 25 & 52 \\
\hline & $65-80$ & 22 & 18 & 40 \\
\hline & $>80$ & 8 & 3 & 11 \\
\hline \multirow{3}{*}{$\begin{array}{l}50.001 \\
500.000\end{array}$} & $50-65$ & 34 & 32 & 66 \\
\hline & $65-80$ & 29 & 23 & 52 \\
\hline & $>80$ & 9 & 4 & 13 \\
\hline \multirow{4}{*}{$>500.000$} & $50-65$ & 32 & 30 & 62 \\
\hline & $65-80$ & 27 & 21 & 48 \\
\hline & $>80$ & 9 & 4 & 13 \\
\hline & TOTAL & 275 & 225 & 500 \\
\hline
\end{tabular}

Table 2: Distribution of stores

\begin{tabular}{|l|c|}
\hline Store & Number \\
\hline Drugstore & 47 \\
\hline $\begin{array}{l}\text { Appliances and } \\
\text { electronic devices }\end{array}$ & 90 \\
\hline Clothes and textiles & 102 \\
\hline Shoes & 19 \\
\hline Kitchen Furniture & 47 \\
\hline Furniture & 45 \\
\hline Total & $\mathbf{3 5 0}$ \\
\hline
\end{tabular}

The objective of the interviews is to obtain information about problems of use of products, and the type and the importance of the problem. The problems are classified by means of semantic differential $^{3}$.

\section{Definition of SIMPLIT protocol}

The test protocol for any type of product is based on a preliminary definition of the problems related with the use, compliance with standards and recommendations related to the problems, and test with 8-10 users ${ }^{4}$. The test with users includes two techniques: task analysis ${ }^{5}$ and think aloud ${ }^{6}$.

During the first phase, the product must comply mandatory regulations such as Electromagnetic legislation ${ }^{7}$ for electronic devices or specific directives of each product or application field ${ }^{8}$.

Moreover, a group of four experts agrees the minimal accessibility and usability requirements of the product based on scientific literature and standards, including Spanish ${ }^{9}$, European ${ }^{10}$ and ISO standards ${ }^{11}$. The experts assess the accomplishment of minimal requirements taking into account the expected use and basic tasks of the product, and its relation with the physical, sensorial and cognitive capabilities of older persons.

The product compliance with obligatory regulation and minimal usability requirements is mandatory to start the second phase.

During the second phase, the first step is to define the experimental design: user characterization, taking into account the target group of the product, and definition of the basic of regular use, basic of nonregular use and secondary tasks of the product.

Before start the usability tests, users perform a set of functional test to ensure that fit with user characterization. The observer provides a brief explanation about product use, only for products of Group 1 and 2. Users have three repetitions to correctly perform each task: the first repetition without help, the second repetition with support of product instructions and the third repetition with support of verbal instruction of the observer. Moreover, in the case of products of Group 1 (Table 3), if users need to perform the third repetition, they must perform a fourth repetition without any kind of help to demonstrate that they know how to perform the task

During user tests, the observer records task accomplishment, spent time, errors (type, frequency and seriousness of problems), need of support and number of repetitions needed for the successful fulfilment of the task. Finally, the observer makes a personal interview to the users to obtain qualitative information about their opinion of the ease of use of the product, advantages and disadvantages.

The third step is to process the recorded data to assess the effectiveness and efficiency of each task based on task accomplishment, spent time and number of errors, and number of repetitions. The success threshold of each parameter depends on product category.

Finally, a product gets the SIMPLIT certificate based on the effectiveness and efficiency of the basic tasks. The effectiveness is prioritized over efficiency and the tasks with regular use over the tasks with non-regular use.

Moreover, the product receives a rating from 1 to 5 "stars" depending on its performance level, which depends on the percentage of efficient basic tasks and the percentage of effective and efficient secondary tasks. 


\section{Validation of SIMPLIT protocol}

We have tested the protocol with four practical cases that covers low-tech and hi-tech products: wardrobe, activity park, oven and mobile telephone.

This has allowed adapting the test protocols in order to pass the conformity assessment of a quality certification body (www.aenor.es).

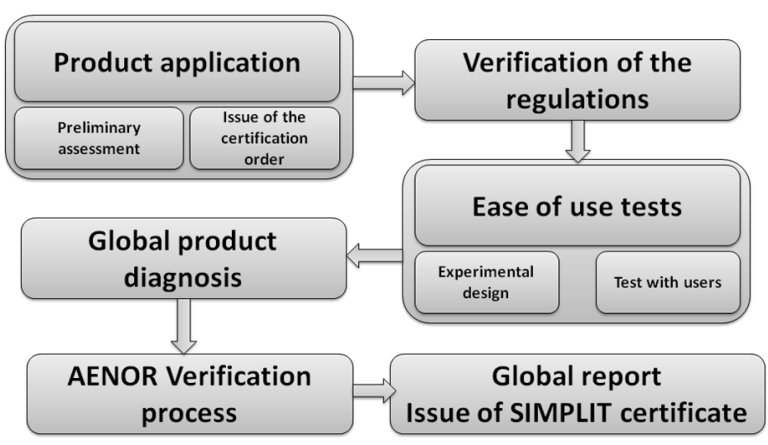

Fig.1. Process to obtain SIMPLIT certificate.

\section{RESULTS}

Map of products and problems.

The products have been classified in 5 categories with different characteristics (Table 3): technology level, need of instructions, need of learning, number of body functions or body parts that interacts with the product (Interaction level), and personal use (only for group 5).

Table 3: Products categories

\begin{tabular}{|l|l|}
\hline GROUP & CHARACTERISTICS \\
\hline $\begin{array}{l}\text { Group 1 } \\
\text { Momples: } \\
\text { Home automa- } \\
\text { tion device }\end{array}$ & $\begin{array}{l}\text { High technology } \\
\text { Low interaction } \\
\text { Instructions required } \\
\text { Learning required }\end{array}$ \\
\hline $\begin{array}{l}\text { Group 2 } \\
\text { Examples: }\end{array}$ & Medium technology \\
Oven & High interaction \\
Microwave & Instructions required \\
\hline $\begin{array}{l}\text { Group 3 } \\
\text { Examples: }\end{array}$ & Low technology \\
Bed & Medium interaction \\
Shower & No instructions \\
& No learning \\
\hline Group 4 & Use in basic activities \\
Examples: & Low technology \\
Knife & High interaction \\
Glass & Instructions required \\
\hline $\begin{array}{l}\text { Group 5 } \\
\text { Examples: }\end{array}$ & No learning \\
Clothes & Low technology \\
Glasses & High interaction \\
Instructions required & No learning \\
\hline & Use in basic activities \\
& Personal equipment \\
\hline
\end{tabular}

The types of problems for each product category are:

Table 4: Type of problems

\begin{tabular}{|l|l|}
\hline Problems & Groups \\
\hline To reach in height & 2,3 \\
\hline To reach deep & $2,3,4$ \\
\hline Bending, Maintain posture & $2,3,4$ \\
\hline Force (push and pull) & $2,3,4$ \\
\hline Force (use of controls) & $2,3,4,5$ \\
\hline Mobility (push and pull) & $2,3,4,5$ \\
\hline $\begin{array}{l}\text { Coordinate movements (simultaneous } \\
\text { actions) }\end{array}$ & $2,3,4,5$ \\
\hline Dexterity (hands) & All \\
\hline Dexterity (rotate and press) & All \\
\hline Security (bumps and cuts) & $2,3,4,5$ \\
\hline Read signs (size, understanding, contrast) & $1,2,3$ \\
\hline Memorizing steps (illogical, complex) & $1,2,3$ \\
\hline Lack of feedback & $1,2,3,5$ \\
\hline Read instructions (font size, contrast) & $1,2,5$ \\
\hline Understand instructions (illogical, complex) & $1,2,5$ \\
\hline
\end{tabular}

\section{Validation of the protocol}

The validation of the protocol was performed with the four practical cases (wardrobe, activity park, oven and mobile telephone) comparing user tests with heuristic evaluation performed by four experts on usability and older people ${ }^{4}$.

The reliability of the methodology was checked comparing the tests results performed with two set of users and four observers during the assessment of each product. Moreover, the protocols have passed the conformity assessment of AENOR.

The results of these tests allowed adjusting the success thresholds of effectiveness (task accomplishment) and efficiency parameter (spent time, number of errors, necessity of support and number of repetitions).

\section{CONCLUSIONS}

A reliable methodology has been set up, combining expert assessment with user tests, to assess the ease of use of any product by older persons. We have applied SIMPLIT process to more than 20 products covering from mobile telephone, tablets, software, furniture, kitchen equipment to telecare systems. Until now, six products have obtained the SIMPLIT certificate.

In parallel, we have launched a set of dissemination activities to inform older person and companies about the SIMPLIT certificate. Moreover, we have carried out some formative initiatives to train older 
persons to assess, choose and buy products fitted to their needs and capabilities.

\section{References}

1. Barbera, R., Poveda, R., Los hábitos de compra de las personas mayores, importancia de la tecnología. Revista de Biomecánica, 2008.

2. Ruiz-Olabuenaga, J.I., Metodología de la Investigación cualitativa, 4th edition. Universidad de Deusto, Bilbao, 2007.

3. Osgood, C.E., Suci, G.J., Tannebaum, P.H., The measurement of meaning, University Illinois Press, 1957.

4. Nielsen, J., Molich R., "Heuristic Evaluation of User Interfaces", CHI '90 Proceedings, 1990.

5. Fisk, A.D., Rogers, W.A., Charness, N., Czaja, S.J., Sharit, J., Designing for older adults. CRC Press, 2004.

6. Van Someren, M.W., Barnard, Y.F., Barnard, J.A.C., Think Aloud Method. Academic Press. London, 1994.

7. Electromagnetic Compatibility (EMC) Legislation: Directive CE 2004/108

8. Directive 1999/5. Radio and Telecommunications Terminal Equipment.

9. UNE ISO 9241-20. Ergonomía de la interacción persona-sistema. Parte 20: Pautas de accesibilidad para equipos y servicios de tecnologías de información/comunicación, 2004.

10. ETSI EG 2002 116. Human Factors (HF); Guidelines for ICT products and services; "Design for All". ETSI EG, 2002.

11. ISO 22411. Ergonomics data and guidelines for the application of ISO/IEC Guide 71 to products and services to address the needs of older persons and persons with disabilities, 2008. 